\title{
The Japanese Urban System from the Standpoint of Large Private Firms' Head Offices and Branch Offices, 1995
}

\author{
Kazutoshi ABE \\ Aichi University of Education, Kariya, Aichi 448-8542, Japan
}

\begin{abstract}
This paper aims to examine the current situation in Japan's largest cities and describe the Japanese urban system, by analyzing the distribution of the management function (head offices and branch offices) of the country's largest private firms. This study is based on data for 2,241 private firms. The status of cities under study is compared from various standpoints. An attempt is made to throw light on the inter-connections between cities. Finally, a model of the urban system of major cities is proposed. Twenty-nine cities were chosen for study (Figure 1), each of which has more than 10 firm head offices or 300 branch offices (Table 2). Clearly, the largest number (919) of head offices is found in Tokyo. This is followed by Osaka, in which the head offices of 314 firms are located. However, it should be noted that in recent years, more and more firms have adopted the system of multiple head offices (Table 3). Including such firms, the number of private firms having their head offices in Tokyo is 1,105 , which represents $49.3 \%$ of the total.

Tokyo houses the largest number of branch offices, as well. As was the case for head offices, the city with the second largest number of branch offices is Osaka. After Tokyo and Osaka, Nagoya, Fukuoka, Sendai, Hiroshima, and Sapporo are the cities with the most branch offices.

The author analyzed the hierarchical relationships of branch offices (Table 5), the type of industry (Table 6), city territories served by branch offices (Table 7 and Figure 4), head office and branch office size (Table 9) and inter-urban connectivity (Table 10). The author proposes a model for the urban system based on the findings of preceding analyses (Figure 6). This model clearly shows the complex networks of inter-connections established between major Japanese cities.
\end{abstract}

Key words: large private firm, head office, branch office, urban system, Japan

\section{Introduction}

This study aims to examine the urban system in Japan and describe the current situation in Japan's largest cities, by analyzing the management function distribution among head offices and branch offices of the country's largest private firms.

First, the status of cities will be compared by indicating the number of head offices and branch offices located in each. Then, by examining the territories served by branch offices, an attempt will be made to delimit the vast economic territories of major cities. Finally, an attempt will be made to throw light on the numerous inter-connections between cities by counting the branch offices located in each city of private firms with head offices in Tokyo,
Osaka and Nagoya. In this paper, the word Tokyo refers to the 23 wards constituting the administrative city area. A description of the urban system of major cities will be made by bringing together findings concerning economic territories and those concerning the numerous inter-connections between cities. In the following paragraphs, the author explains why his attention was drawn to the function of offices in particular in this study.

Let us take a metalworking company as an example. The organization chart of such a company usually comprises the administrative section (head office and branches) and the production section (factories). Industrial geographers are traditionally interested in the area of the production function, and have centered their analyses on the location of factories and the impact of this on cities and regions. Little 
Table 1. Workforce size variation in the Kirin brewery's factories, head office and branch offices

\begin{tabular}{ccccccc}
\hline & \multicolumn{5}{c}{ Factories } \\
\cline { 2 - 6 } Year & Yokohama & Amagasaki & Sendai & Hiroshima & $\begin{array}{c}\text { Tokyo } \\
(23 \text { wards })\end{array}$ & Nagoya \\
\hline 1961 & 1,011 & 580 & 289 & 469 & 366 & 185 \\
1970 & 1,132 & 734 & 452 & 630 & 437 & 874 \\
1985 & 742 & 425 & 295 & 118 & 295 & 587 \\
1995 & 540 & 253 & 219 & 292 & 189 & 465 \\
\hline
\end{tabular}

\begin{tabular}{|c|c|c|c|c|c|c|c|c|}
\hline \multirow[b]{2}{*}{ Year } & \multirow{2}{*}{$\begin{array}{c}\text { Head office } \\
\text { Tokyo } \\
\text { (23wards) }\end{array}$} & \multicolumn{7}{|c|}{ Branch offices } \\
\hline & & $\begin{array}{c}\text { Tokyo } \\
\text { (23wards) }\end{array}$ & Sapporo & Sendai & Nagoya & Osaka & Hiroshima & Fukuoka \\
\hline 1961 & 173 & 140 & 19 & 35 & 54 & 56 & 44 & 50 \\
\hline 1970 & 287 & 269 & 29 & 58 & 74 & 117 & 70 & 70 \\
\hline 1985 & 614 & 331 & 42 & 75 & 113 & 174 & 75 & 86 \\
\hline 1995 & 857 & 445 & 87 & 157 & 206 & 359 & 187 & 247 \\
\hline
\end{tabular}

Source: Annual company reports 1961, 1970, 1985 and 1995.

attention was given to the administrative section in studies of cities until the 1960s, when the number of studies on cities based on the administrative section rose. Researchers subsequently began to recognize the office function as an important driving force in urban development.

Let us now take a specific example, the Kirin brewery, which is one of the biggest breweries in Japan. Table 1 shows the workforce size in offices and factories belonging to the company and illustrates major employee increases and decreases in 1961, 1970, 1985 and 1995. Between 1970 and 1995, employee numbers rose continuously at the head office and branch offices, whereas the numbers in factories fell continuously during the same period. The latter was largely a result of the two oil crises in the 1970s. Production did not decrease along with factory employee numbers. In fact, it increased as mechanization and automation developed.

On the other hand, the increase in employee numbers at head and branch offices was in response to an increase in administrative tasks such as market research. Despite office work becoming significantly mechanized and rationalized, this did not result in a reduction of employee numbers, as was the case in the factories in the production section. This indicates that automatization in data processing does not affect personnel numbers in areas responsible for analyzing data or making decisions in the strategic marketing section. As these tasks became more important to the companies, the numbers of people responsible for them rose.

As a result of these factors, some urban geographers have become more interested in the study of the head offices and branch offices of private firms, especially of large firms (Abe 1977, 1979, 1984, 1991, 1996; Economic Planning Agency 1964; Nagai 1967; Nagai and Miyaji 1967). Based on these analyses, the present paper will endeavor to rank major Japanese cities, and conduct a comparative study of cities and urban systems, by analyzing the location of head and branch offices of large private companies in Japan's major cities.

\section{Data}

As large private Japanese firms constitute the subject of this paper, it is necessary to define the firms which will be included in the study. While the study will concentrate on the head offices and branch offices of private firms, it would be neither practical nor pertinent to study every private Japanese firm. It will suffice to study the head offices and branches of the largest private firms, since these are the 
Table 2. Population of major cities and number of head offices and branch offices located in each city

\begin{tabular}{|c|c|c|c|}
\hline \multirow[b]{2}{*}{ 1. Tokyo (23wards) } & head office & \multirow{2}{*}{$\frac{\text { branch office }}{1,515}$} & \multirow{2}{*}{$\frac{1995 \text { population (thousands) }}{7,967}$} \\
\hline & $919 \quad(41.0)$ & & \\
\hline 2. Osaka & $314 \quad(14.0)$ & 1,377 & 2,602 \\
\hline 3. Nagoya & $88 \quad(3.9)$ & 1,348 & 2,152 \\
\hline 4. Fukuoka & $33 \quad(1.5)$ & 1,182 & 1,285 \\
\hline 5. Sendai & 9 & 1,035 & 971 \\
\hline 6. Hiroshima & $21 \quad(0.9)$ & 967 & 1,109 \\
\hline 7. Sapporo & $24 \quad(1.1)$ & 961 & 1,757 \\
\hline 8. Yokohama & $(2.2)$ & 657 & 3,307 \\
\hline 9. Takamatsu & 10 & 551 & 331 \\
\hline 10. Kobe & (2.5) & 506 & 1,424 \\
\hline 11. Shizuoka & 4 & 494 & 474 \\
\hline 12. Kanazawa & 11 & 485 & 454 \\
\hline 13. Niigata & 9 & 481 & 495 \\
\hline Chiba & 9 & 481 & 857 \\
\hline 15. Okayama & 7 & 466 & 616 \\
\hline 16. Kyoto & $(2.1)$ & 458 & 1,464 \\
\hline 17. Omiya & 5 & 402 & 434 \\
\hline 18. Kitakyushu & 16 & 377 & 1,020 \\
\hline 19. Kumamoto & 6 & 350 & 650 \\
\hline Kagoshima & 5 & 350 & 546 \\
\hline 21. Utsunomiya & 5 & 343 & 435 \\
\hline 22. Hamamatsu & 7 & 310 & 562 \\
\hline 23. Nagano & 4 & 305 & 359 \\
\hline 24. Mito & 1 & 303 & 246 \\
\hline 25. Toyama & 8 & 300 & 325 \\
\hline 26. Kawasaki & $(1.0)$ & 180 & 1,203 \\
\hline 27. Sakai & 13 & 165 & 803 \\
\hline 28. Amagasaki & $(0.9)$ & 75 & 489 \\
\hline \multirow[t]{2}{*}{ 29. Nishinomiya } & 11 & 68 & 390 \\
\hline & $504 \quad(22.5)$ & & \\
\hline total & \multicolumn{2}{|l|}{$2,241(100.0)$} & \\
\hline $\begin{aligned} \text { ii) } & \text { The State } \\
\text { iii) } & \text { Survey by } \\
\text { iv) } & \text { Population }\end{aligned}$ & $\begin{array}{l}\text { Japanese Compan } \\
\text { e Companies } 199 \\
\text { or } \\
\text { om } 1995 \text { Populat }\end{array}$ & $\begin{array}{l}996 \text { by the 'Niho } \\
\text { d by 'Diamond, I } \\
\text { of Japan. }\end{array}$ & i Shinbun' \\
\hline
\end{tabular}

firms which most significantly influence the Japanese economy as a whole. Accordingly, the study will limit itself to those firms listed in the Annual Nikkei Japanese Company Report published by the 'Nihon Keizai Shinbun' newspaper; that is, the private firms which are rated as dominating, and which in reality do dominate the economy of the country. The 2,241 private firms listed in the above report in 1995 and also listed on the various Stock Exchanges in the country will form the basis of this study.

The principal reference data are taken from the Annual Nikkei Japanese Company Report, and the State of Japanese Companies published by 'Diamond, Inc.'. These reports include all head offices of firms listed on the stock exchange, but do not mention certain branch offices of these firms. Accordingly, data concerning firms in the finance and insurance area are taken from the 'Annual Report on Financial Companies', published by the 'Nihon Kinyu Tsushinsha' agency. Data concerning firms not mentioned in the Japanese Company Report were collected from a survey carried out by the author. Firms which did not respond to the questionnaires were visited by the author in 


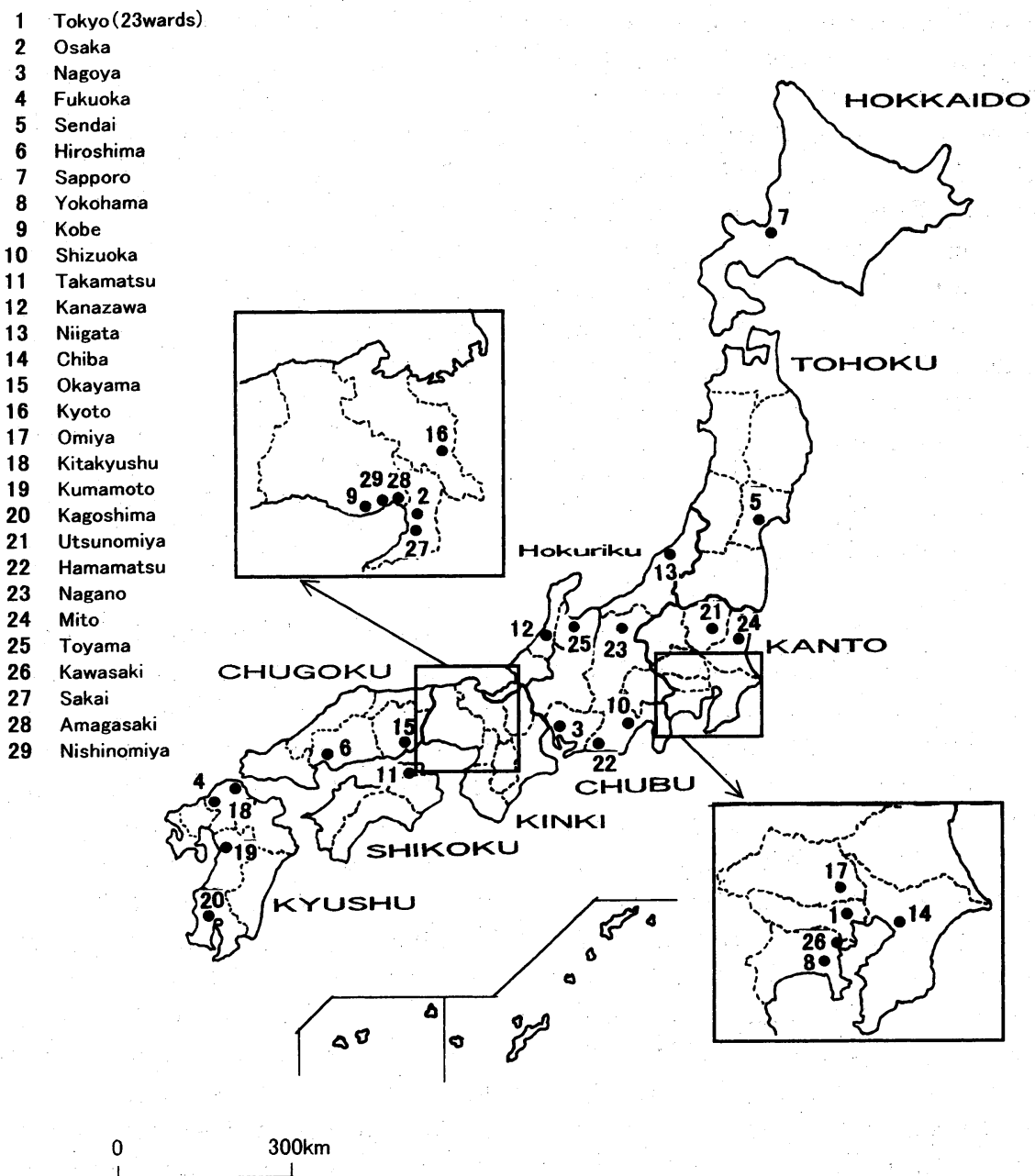

Figure 1. Outline of Japan, regions and the location of cities under study. Notes:

1) a) The regional boundaries are marked by a continuous line.

b) The prefectural borders are marked by a dotted line.

2) The Hokuriku region is often considered part of the Chubu region.

3) Only the cities under study are shown.

4) Small Japanese islands are not shown.

order to collect the missing data. Data on branch location was collected from each of the 2,241 private firms. The type of industry of these 2,241 firms is listed in Table 4 shown later.

\section{Situation of Head Offices and Branch Offices in Major Cities}

\section{Cities under study}

The cities chosen for study are those having more than 10 company head offices or 300 branch offices. Table 2 shows the 29 cities falling in this category. The site of each city is shown in Figure 1. In terms of population (Table 2), Tokyo has the largest number of inhabitants $(7,967,000)$ and Mito has the smallest $(246,000)$. Mito is the 87th largest city in Japan in terms of population. As shown by Table 2, the distribution of branch offices of the largest firms does not strictly depend upon the population size of cities.

The following method was used to specify the number of head offices and branch offices 
shown in Table 2. Concerning head offices, the calculation is based on one head office per firm. However, it should be noted that in recent years, more and more firms have adopted the system of multiple (usually 2 ) head offices. The number of head offices shown in Table 2 for each firm is the legally registered number.

Concerning branch offices, the assumption is that, for each firm, there is one branch in each city, even though some firms (particularly banks) have several branches in one city. In addition, some manufacturing firms have two branches in the same city, but Table 2 does not take this into account. The number of branches shown in Table 2 gives an idea of the percentage of firms having branches in a given city. For example, looking at Tokyo, the number of branches listed $(1,515)$ indicates that $67.6 \%$ of the 2,241 firms have branches in Tokyo.

There are 47 prefectures in Japan, each having its own administrative center. Twentyfive administrative centers do not appear in this study. However, 22 of the 29 cities under analysis are prefectural administrative centers. Seven cities which are not prefectural administrative centers also appear in the study. These are Omiya, Kitakyushu, Hamamatsu, Kawasaki, Sakai, Amagasaki and Nishinomiya. These cities have sizeable populations. Their development has greatly benefited from industry, although, today, the size of their population does not necessarily have a direct relation with their industrial activity. In Omiya, Kawasaki, Sakai and Nishinomiya, for example, the increase in population is rather a consequence of the expansion of the metropolitan areas of Tokyo and Osaka.

\section{Head offices}

First, we will analyze the sites of head offices in major cities. Clearly, the largest number of head offices is to be found in Tokyo, where 919 firms have their head offices. This is $41.0 \%$ of the 2,241 firms studied. Osaka, in second place, contains the head offices of 314 firms, or $14.0 \%$ of the total number of firms, which is $34.2 \%$, or about a third of the number located in Tokyo. Next, Nagoya has the head offices of 88 firms (3.9\% of the total), Kobe of 57 firms (2.5\% of the total), Yokohama of 50 firms (2.2\% of the total),
Table 3. Multiple head office system

\begin{tabular}{|c|c|c|}
\hline $\begin{array}{l}\text { First head office } \\
\text { (legally registered) }\end{array}$ & $\begin{array}{c}\text { Second } \\
\text { head office }\end{array}$ & \\
\hline Osaka & Tokyo (23wards) & 83 \\
\hline Cities other than Osaka & Tokyo (23wards) & 103 \\
\hline Tokyo (23wards) & Osaka & 8 \\
\hline $\begin{array}{l}\text { Cities other than } \\
\text { Tokyo ( } 23 \text { wards) }\end{array}$ & Osaka & 18 \\
\hline Other cases & & 54 \\
\hline Total & & 266 \\
\hline \multicolumn{3}{|c|}{$\begin{array}{l}\text { Sources: The annual Nikkei Japanese Company Report } \\
1996 .\end{array}$} \\
\hline $\begin{array}{l}\text { The State of } \\
\text { published by 'Dia' }\end{array}$ & $\begin{array}{l}\text { apanese Companies } \\
\text { hond, Inc.' }\end{array}$ & 1996 \\
\hline
\end{tabular}

and Kyoto of 48 firms (2.1\% of the total). Figure 1 shows that all these cities are located in the central part of Japan, along the Pacific coast. These six cities have often been called the six greatest Japanese cities because of their historical importance and population size.

The numbers referred to here were arrived at by taking into account only those head office numbers legally registered. As mentioned earlier, the number of Japanese companies adopting a system of multiple head offices has been rising in recent years. Table 3 shows how many firms are using this system. In 1995, 266 of the 2,241 firms used this system, which is $11.9 \%$ of the total number of firms under study, and of these 266 firms 186 (69.9\%) had their second head office in Tokyo and 26 firms (9.8\%) had them in Osaka. Eighteen firms having their principal head office in a city other than Tokyo, have their second head office in Osaka. Indeed, most of these 18 firms have their original head office in the Osaka metropolitan area.

On the other hand, firms having their second head office in Tokyo have originated in cities all over Japan. This denotes the significant difference in influence between Tokyo and Osaka. However, the most significant point about multiple head offices is the fact the 83 firms having their original head office in Osaka have their second head office in Tokyo. Osaka has long been the second largest city in Japan and has always been Tokyo's rival in many fields. Many firms have therefore established their head offices in Osaka. Nevertheless, as indi- 
Table 4. Type of industry of firms and number of head offices by major city

\begin{tabular}{|c|c|c|c|c|c|c|c|c|c|c|c|c|c|c|}
\hline Cities & 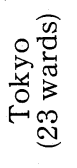 & $\begin{array}{l}\frac{\pi}{\pi} \\
\mathbb{\pi} \\
0\end{array}$ & 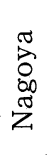 & 芒 & 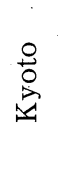 & 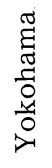 & 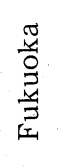 & 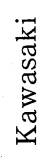 & 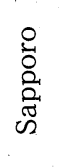 & 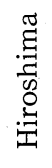 & 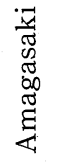 & 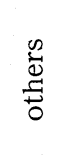 & 营 & 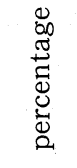 \\
\hline $\begin{array}{l}\text { agriculture, fisheries and } \\
\text { forestry }\end{array}$ & 6 & & & & & 1 & & & & & & 1 & 8 & 0.4 \\
\hline mining & 9 & & 1 & & & & 1 & & & & & & 11 & 0.5 \\
\hline construction & 91 & 29 & 6 & 1 & & 4 & 3 & & 2 & 2 & & 33 & 171 & 7.6 \\
\hline food & 51 & 7 & 4 & 9 & 2 & 5 & 3 & & 5 & 2 & & 30 & 118 & 5.3 \\
\hline textiles & 28 & 22 & 4 & 4 & 11 & & & & & & 1 & 30 & 100 & 4.5 \\
\hline paper and allied products & 11 & 5 & 1 & & & & & & & & 1 & 13 & 31 & 1.4 \\
\hline chemicals & 109 & 38 & 2 & 4 & 4 & 2 & 1 & 2 & 1 & 2 & 3 & 41 & 209 & 9.3 \\
\hline rubber goods and ceramics & 31 & 8 & 4 & 4 & & 1 & & 1 & & 1 & 1 & 27 & 78 & 3.5 \\
\hline iron, steel and machinery & 255 & 69 & 20 & 11 & 16 & 20 & 4 & 17 & 1 & 4 & 14 & 252 & 683 & 30.5 \\
\hline other manufactures & 26 & 11 & 4 & 2 & 3 & 1 & & & & & & 19 & 66 & 2.9 \\
\hline commerce and trading & 113 & 66 & 21 & 7. & 6 & 4 & 10 & 1 & 6 & 4 & & 76 & 314 & 14.0 \\
\hline banks and financial leasing & 34 & 11 & 7 & 3 & 2 & 2 & 6 & & 5 & 3 & & 74 & 147 & 6.6 \\
\hline securities & 21 & 5 & 1 & & & & & & & & & & 27 & 1.2 \\
\hline insurance & 12 & 2 & & & & & & & & & & & 14 & 0.6 \\
\hline real estate & 20 & 10 & 1 & 1 & & & & & & & 1 & 3 & 36 & 1.6 \\
\hline $\begin{array}{l}\text { transportation and commu- } \\
\text { nication }\end{array}$ & 53 & 12 & 6 & 11 & 3 & 6 & 1 & 1 & 1 & 1 & & 22 & 117 & 5.2 \\
\hline television station & 4 & & & & & & & & & & & & 4 & 0.2 \\
\hline $\begin{array}{l}\text { electric power companies } \\
\text { and gas companies }\end{array}$ & 2 & 2 & 2 & & & & 2 & & 2 & 2 & & 7 & 19 & 0.8 \\
\hline service & 43 & 17 & 4 & & 1 & 4. & 2 & & 1 & & & 16 & 88 & 3.9 \\
\hline total & 919 & 314 & 88 & 57 & 48 & 50 & 33 & 22 & 24 & 21 & 21 & 644 & 2,241 & 100.0 \\
\hline
\end{tabular}

Source: See Table 2.

cated in Table 3, 83 firms have their second head office in Tokyo. And since these second head offices play a more important role than the first for the firms concerned, it may be no exaggeration to say that the 83 head offices in Osaka are relegated to branch office level.

In Japan, a problem of regional structure became apparent in the 1980 s, with the polarization of activities in Tokyo, which brought about a deterioration in the urban function of Osaka. Reasons for this concentration of activities in Tokyo are varied: 1) the large amounts of information available there, 2) its cosmopolitanism, 3) its many research centers, 4) its position as a mass media hub, 5) the enormous market potential there, and 6) its proximity to central government (Komori 1965; Abe 1990). These characteristics themselves are not actually recent; they have existed since Tokyo became the capital of Japan, about 130 years ago. Many firms have transferred their head offices to Tokyo during this century, adding to the number of head offices already established there.

There are two reasons firms have established a second head office in Tokyo, rather than transfer their principal head office there. The first is because of the Japanese tax system. The municipal resident tax (corporation) is collected by the tax authority where the head office of a firm is registered. This means that, if a firm transfers its head office from one local authority to another, the tax revenues of the first will decrease. The local authorities thus oppose a firm transferring its head office to another city. The second reason is that there often exists a long-standing relationship between a firm and local authorities. This is the reason for the growing opposition against head office transfer and it is not, therefore, easy for firms to dissociate themselves completely from the cities from 
which they originate. However uneconomic it may appear, these factors significantly affect the decisions taken by firms.

The reasons cited above are also the two principal reasons for which firms apply the multiple head office system. Firms having their second head office in Tokyo use it in practice as the main head office, and use their legal head office only nominally. Alternatively, they confer important powers on their branch offices in Tokyo. Taking this factor into consideration, the number of private firms having their head offices in Tokyo is not 919 , but $1,105(919+83$ +103 ), which represents $49.3 \%$ of the total number of firms.

Now, let us focus on these firms' type of industry. Table 4 shows the type of industry of each firm under study, and firms based in cities having more than 20 head offices. According to this table, the iron, steel and machinery industries are the most important and are represented by 683 firms, that is, $30.5 \%$ of the total. Industries concerned with food, textiles, chemicals, paper and allied products, rubber goods and ceramics, iron, steel and machinery, and other manufactured goods (that is, all manufacturing industries) are represented by 1,285 firms, or $57.3 \%$ of the total. Manufacturing industries therefore make up the largest number of large Japanese companies, followed by commerce and trading, with 314 firms (14.0\%), construction with 171 firms (7.6\%) and banks and financial leasing companies with 147 firms (6.6\%). Agriculture, fisheries and forestry, with 8 firms, account for only $0.4 \%$ of the total number of firms.

Of the 919 firms having their head office in Tokyo, 255 belong to the iron, steel and machinery industries, representing $27.7 \%$ of the total. This number is slightly lower than the $30.5 \%$ of the total number of firms studied accounted for by iron, steel and machinery firms. Five-hundred and eleven manufacturing firms, or $55.6 \%$ of the total, have their head offices in Tokyo. This number, also, is slightly lower than the $57.3 \%$ of the total number of firms accounted for by manufacturing firms.

The total number of banks and financial leasing, securities and insurance companies with head offices in Tokyo is therefore 67 , or $7.3 \%$, of the total number of firms having their head offices in Tokyo. Although it is generally assumed that most financial institutions are based in Tokyo, the number of these institutions based there is not in fact so high, because a number of powerful, local financial institutions are based in other cities. Of course, the credit balance denoting the activities of the financial institutions is much higher in organizations based in Tokyo (Takahashi 1983).

Osaka is the city with the second largest number of head offices, but it remains quite far behind Tokyo. Even when taking into consideration different types of industry, there is none in which Osaka is better represented in head offices than Tokyo. In the area of iron, steel and machinery in particular, Osaka has significantly fewer: 69 firms, or $27.1 \%$ of the number of firms, are based in Tokyo, and this is the principal reason for the inferior economic position of Osaka to Tokyo.

\section{Branch offices}

In this section, we shall look at the situation of the branch offices of private firms in the cities described in Table 2. Tokyo houses the largest number of branch offices, with 1,515 , or $67.6 \%$ of the 2,241 firms under study. On the other hand, the number of firms without a head office or branch

Office in Tokyo is only 294 , or $13.1 \%$ of the total number of firms. This illustrates the importance of Tokyo for private Japanese enterprise.

Of these 294 firms, 27 have head offices or branches in cities near Tokyo, that is, less than 50 kilometers from Tokyo. With head offices located thus, it would not seem advantageous to be based in Tokyo, since the commute to Tokyo would be easy whenever it was deemed necessary to carry out business activities there. Taking such firms into account, the number of firms having neither head office nor branch office in or around Tokyo falls to 215 . The percentage of these firms of the total number is then $9.6 \%$. Only 30 of the firms (9.6\%) having their head offices in Osaka have no branch office in Tokyo, a small minority in comparison with the $90.4 \%$ who do have offices there.

As was the case for head offices, the city with 


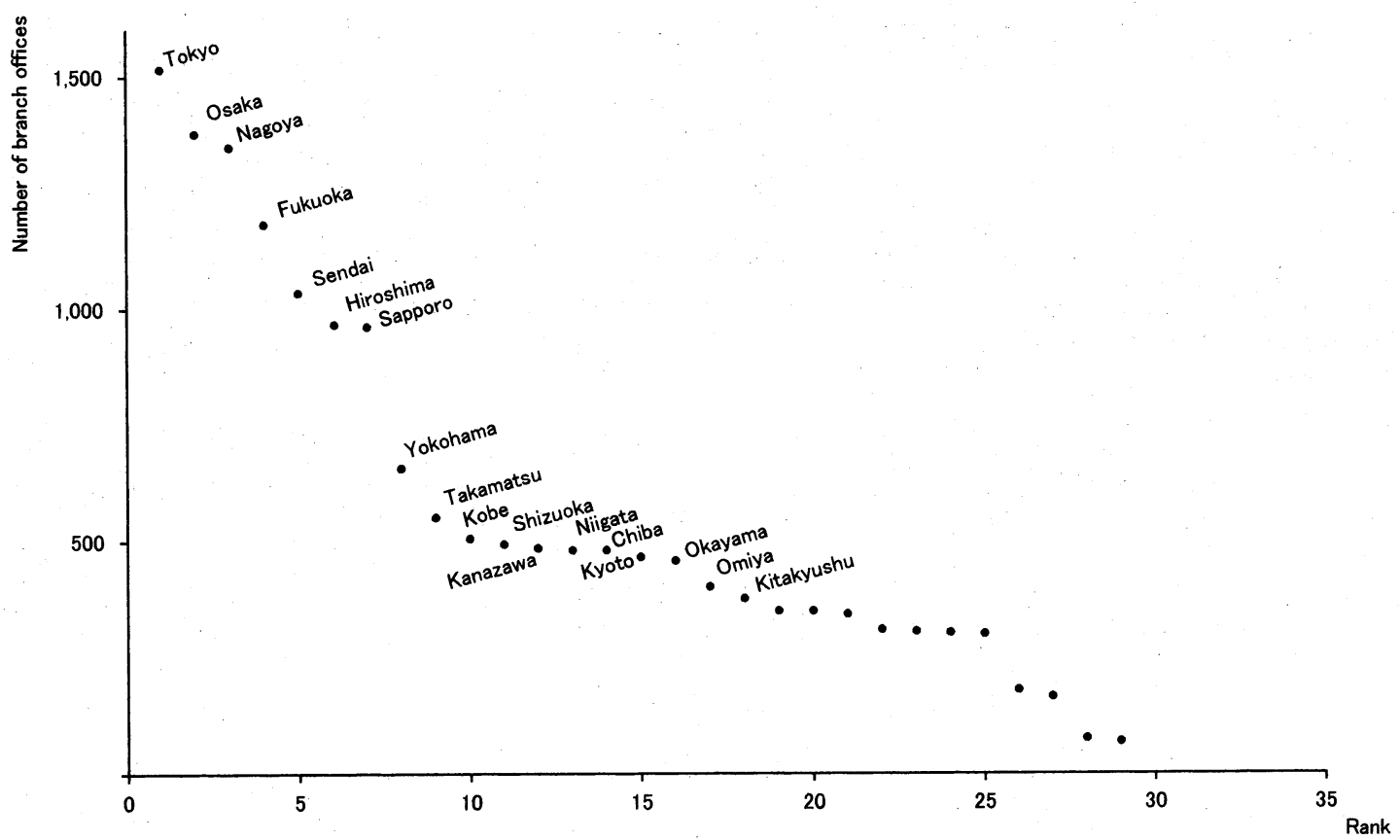

Figure 2. Rank-size curve of major Japanese cities by number of branches.

the second largest number of branch offices is Osaka with 1,377. Six-hundred thirty-two have neither head office nor branch office in Osaka; this is $28.2 \%$ of the total number of firms and a much higher number than was the case for Tokyo. Around Osaka there are also cities (such as Kyoto and Kobe) in which there are head offices, just as there are in the cities on the periphery of the capital. Discounting the 92 firms having head offices in these cities around Osaka, 540 firms have neither head office nor branch office in Osaka, accounting for $24.1 \%$ of the total number of firms under study. Again, this is markedly different compared with Tokyo. Lastly, 238 firms having head offices in Tokyo have no branch office in Osaka. This is $25.9 \%$ of firms with head offices in Tokyo.

After Tokyo and Osaka, Nagoya (1,348 branches) and Fukuoka $(1,182)$ are the cities with most branch offices. In comparison with Tokyo and Osaka, the firms with head offices here are not very numerous, but the number of branches located in each of these cities is almost the same. This illustrates the importance of these cities in Japanese business. After Nagoya and Fukuoka, the cities in which most branch offices are located are Sendai $(1,035$ branches), Hiroshima (967) and Sapporo (961). As shown in Figure 1, these cities are located in the Tohoku, Chugoku and Hokkaido regions, respectively, where each plays the role of regional capital. The branches located in these three cities have the responsibility for their respective areas. We shall return to this point later. Table 2 brings out an important difference between the number of branches located in Sapporo and Yokohama. Figure 2 illustrates this difference. This shows the rank of cities by the number of branch offices located in them. The break in the number of branches located in Sapporo and Yokohama is particularly noticeable. To judge from the number of branch offices located nationwide, it can be said that Tokyo, Osaka, Nagoya, Fukuoka, Sendai, Hiroshima and Sapporo are cities of major importance for private Japanese companies.

There are only 657 branch offices in Yokohama despite a population of 3.31 million. The reason for this is that Yokohama is swallowed up in the agglomeration of Tokyo. Though the population of Yokohama is steadily rising because of its influence on activity in Tokyo, Yokohama possesses neither the capacity nor the urban functions to provide for a vast economic 
Table 5. Hierarchical relationship between branch offices in 1990

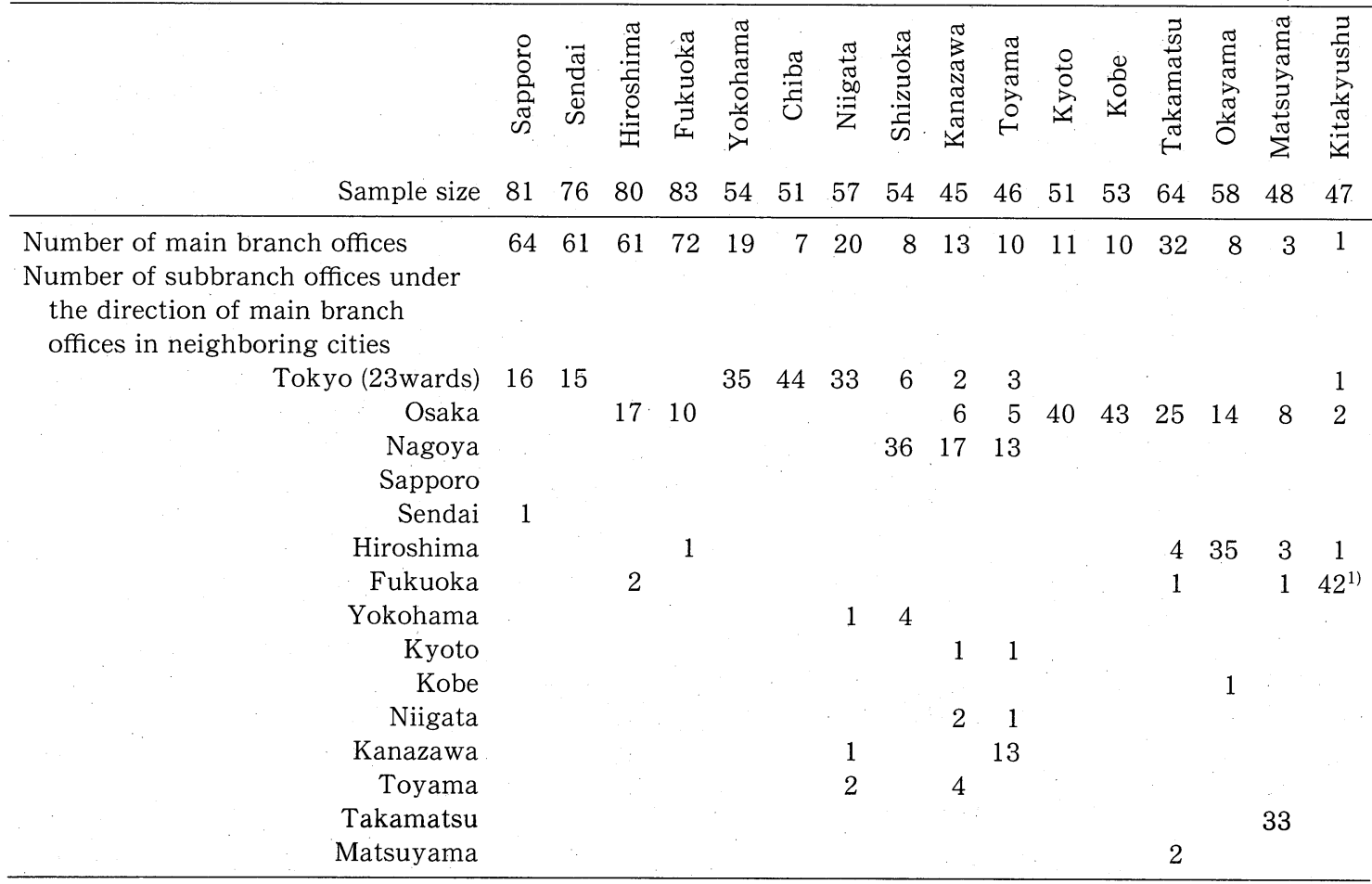

1) For example, 42 of 47 branch offices in Kitakyushu are under the direction of branch offices in Fukuoka. Source: Survey by the author.

area. As will be explained later, there are many firms in the commerce, trading, and construction industries that have close relationships with prefectural administrations and which have developed in proportion with the population of their cities. A similar situation can be observed in Kobe and Kyoto.

The reverse of the phenomenon can be observed in Takamatsu. Though the population is only $331,000,551$ branch offices are established there. Takamatsu is located on the island of Shikoku (Figure 1). While the population is smaller than that of many other cities in Japan and its economic activity (notably industrial) is not as considerable as in other parts of Japan, many branch offices in charge of the whole of the island are located there because of the island's geographical isolation.

Other cities in a similar situation, which house large numbers of branch offices in relation to their population sizes, are Shizuoka, Kanazawa and Niigata. Niigata and Shizuoka con- trol quite vast and dynamic prefectural economic areas. In the case of Kanazawa, the prefecture of Ishikawa, of which it is the administrative center, is quite small, but the common region formed by the two adjoining prefectures (Toyama and Fukui) constitute an ancient unit: the region known as Hokuriku. As a consequence, the presence of numerous branch offices in Kanazawa can be explained by the responsibility these branch offices have over the vast economic Hokuriku area. Fuller details on this point will be provided later.

\section{Branch office hierarchical relationships}

Hierarchical relationships exist between branch offices. While the head office is the highest organ in a firm, controlling branches and factories, not all branches necessarily see themselves as given the same function or amount of power. The number of employees and powers of branch offices located in large cities are not the same as those of branch offices 


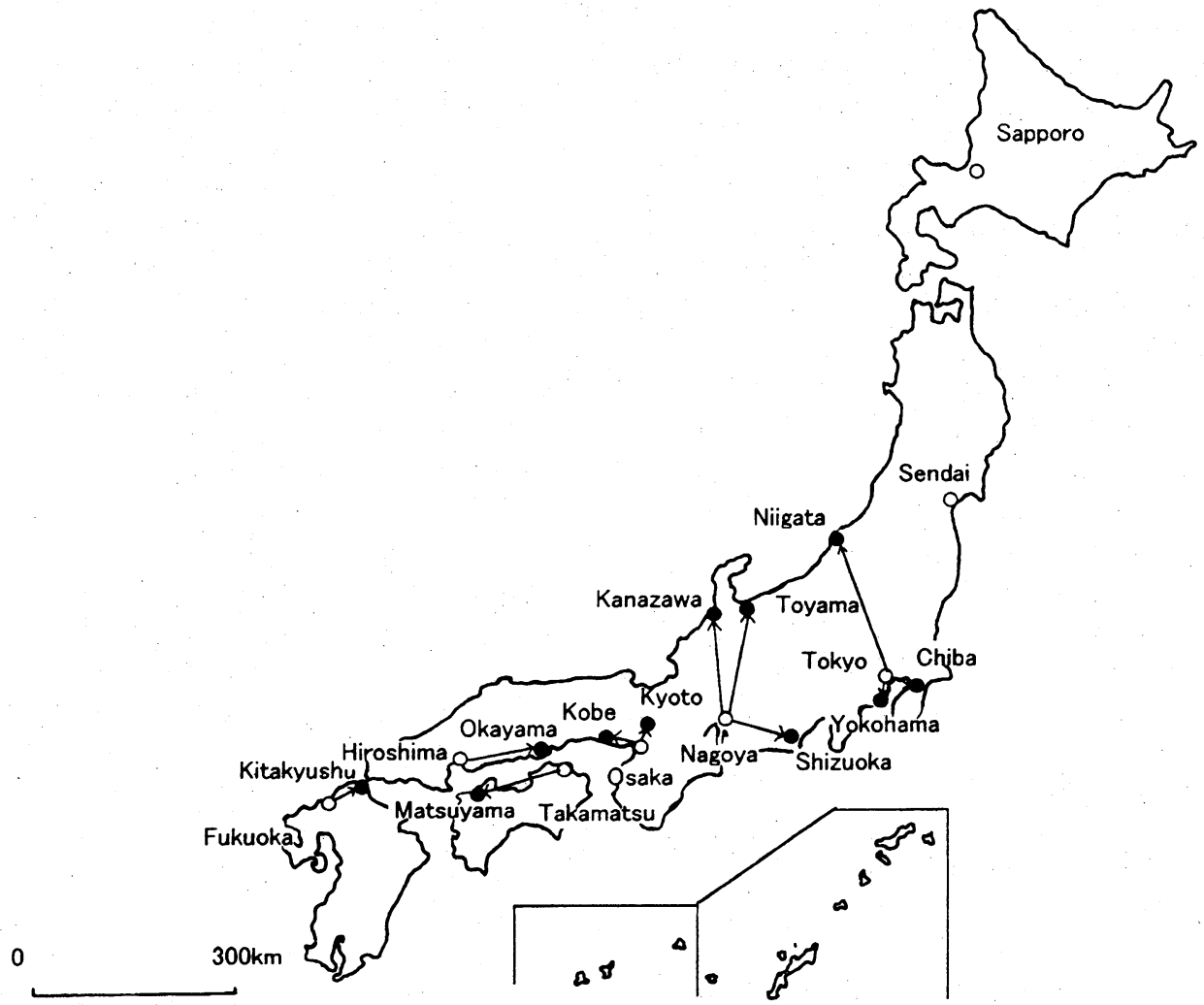

Figure 3. Hierarchical relationships between branch offices. Notes:

City with independent branch offices.

- City in which most branch offices have a subordinate status.

$\longrightarrow$ Most branch offices in cities marked by a filled circle fall under the direction of branch offices of a city marked by an open circle.

located in small towns. Accordingly, there exists a hierarchical organization of relationships between branch offices. This point is not illustrated in Table 2 or Figure 2.

As no data existed on the hierarchical relationships between branch offices in private firms, such data could only be collected by conducting interviews or sending out questionnaires in order to clarify such relationships. An investigation of this kind was carried out in 1990 by the author. The results of the 1990 survey are used in this study. The results of the interviews and questionnaires appear in Table 5. Interviews and questionnaires were not carried out for all firms under study, but for a sample of 100 firms1. This sample will suffice to allow an understanding of branch office relationships.

Tokyo, Osaka and Nagoya being the three major cities in Japan, no branch office located in these cities was under the direction of another branch office in another city. Looking at the cities in Table 5 , it can be seen that certain branch offices located in Sapporo, Sendai, Hiroshima and Fukuoka find themselves under the direction of branch offices located in Tokyo and Osaka. However, a majority of their branch offices are in fact independent of those in Tokyo and Osaka. A large number of branch offices located in Yokohama, Chiba and Niigata are under the direction of branch offices in Tokyo.

The majority of branch offices located in Shizuoka come under the control of branch offices in Nagoya. Most branch offices located in Kanazawa and Toyama stated that they are under the control of branch offices in Nagoya, although some of them operate independently. Nonetheless, the proportion of branch offices 
subordinated, compared with those which enjoy an independent status, clearly shows that cities in Hokuriku do not systematically fall within the influence of Nagoya, despite the fact that the influence of Nagoya here is greater than that of Osaka. Among branch offices in Toyama and Kanazawa, those under the direction of Kanazawa were more numerous than those independent of it.

Branch offices located in Kyoto and Kobe answered more often that they were under the direction of Osaka than that they enjoyed an independent status. In the case of Takamatsu, a majority of branch offices were reported as having the same status and function as those in Osaka, but many branch offices in Takamatsu also reported being under the control of Osaka. Branch offices located in Matsuyama having an independent status are rare. A few reported being independent of branch offices in Osaka, but most responded that they were dependent on branch offices in Takamatsu.

Virtually all branch offices located in Kitakyushu fall under the control of those in Fukuoka. Kitakyushu is a large industrial city of more than a million inhabitants and the branch offices located there depend on those in $\mathrm{Fu}$ kuoka, and are only responsible for the immediate Kitakyushu area.

Figure 3 illustrates the preceding points. Cities in which many branch offices have an equal status to others are marked by circles. Cities in which branch offices control most branch offices situated in other cities in their respective regions are marked with unbroken arrows $(\rightarrow)$ Figure 3 thus clarifies the hierarchical relationship between Japanese cities. Of course, their relationships are intimately connected with the question of city territory. We shall return to this point in a later section.

\section{Type of industry (branch offices)}

In this section, we shall examine the type of industry of branch offices located in the cities under study in this paper. Table 6 shows the different types of industry in which the major branch offices in 18 cities are engaged. The largest number of branch offices in every industrial sector except agriculture, fisheries and forestry, and mining is located in Tokyo. A com- parison of Tokyo with other cities in terms of type of industry and number of branch offices, whether in the iron, steel and machinery, banks and financial leasing, commerce and trading, construction, chemical, or transportation sectors, shows that Tokyo dominates in all sectors. The reason so many branch offices of banks and financial leasing institutions are located in Tokyo is that it is the financial center of Japan, both domestically and internationally. Moreover, as Tokyo houses the highest concentration of head offices, in terms of opportunity it constitutes a city in which it is essential for financial institutions to establish offices. Many financial institutions having their head offices elsewhere, therefore, have branch offices in Tokyo.

The principal difference between the type of industry of branch offices located in Tokyo, Osaka, Nagoya, Fukuoka, Sendai, Hiroshima and Sapporo and of those located in the other cities is a difference in branch office concentration in the iron, steel and machinery, chemical, commerce and trading, banks and financial leasing sectors. There is also a noticeable difference in the number of branch offices located in all 7 of the largest cities, as compared with others for these 4 sectors.

Yokohama is placed immediately behind these 7 cities, in terms of the number of branch offices located there. The most significant difference between the numbers of branch offices located in Yokohama and in Sapporo is the difference in the number of branch offices representing the iron, steel and machinery, and commercial and trading sectors. However, if we compare Yokohama (3.3 million inhabitants), with Takamatsu (331,000 inhabitants), the overall number of branch offices located in Takamatsu is lower, but the number of branch offices of firms in the iron, steel and machinery sector is higher, and the number of branch offices of those in the commerce sector is just 3 fewer than in Yokohama. While the population of Takamatsu is only about $10 \%$ of Yokohama's, the number of branch offices in the iron, steel and machinery, and chemicals sectors, which are dominant industries in Takamatsu, is higher than the number of branch offices in the same sectors located in Yokohama. The reason for this is that Takamatsu is the city in which 
Table 6. Type of industry of branch offices by major city

\begin{tabular}{|c|c|c|c|c|c|c|c|c|c|}
\hline Type of industry & 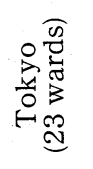 & 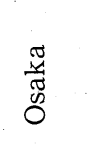 & 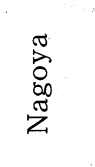 & 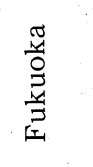 & 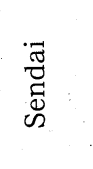 & 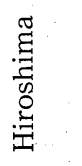 & 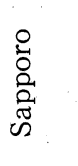 & 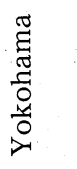 & 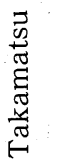 \\
\hline agriculture, fisheries and forestry & 6 & 6 & 7 & 6 & 6 & 5 & 6 & 6 & 3 \\
\hline mining & 1 & 6 & 2 & 3 & 3 & 3 & 4 & 2 & 1 \\
\hline construction & 131 & 128 & 128 & 122 & 121 & 105 & 111 & 123 & 83 \\
\hline food & 81 & 64 & 80 & 70 & 67 & 54 & 65 & 37 & 41 \\
\hline textiles & 61 & 58 & 43 & 32 & 20 & 14 & 30 & 8 & 3 \\
\hline paper and allied products & 21 & 23 & 19 & 13 & 8 & 7 & 7 & 2 & 1 \\
\hline chemicals & 157 & 168 & 162 & 150 & 127 & 117 & 124 & 59 & 77 \\
\hline rubber goods and ceramics & 57 & 58 & 59 & 43 & 36 & 39 & 31 & 11 & 11 \\
\hline iron, steel and machinery & 458 & 422 & 451 & 375 & 347 & 356 & 289 & 160 & 165 \\
\hline other manufactures & 53 & 39 & 51 & 42 & 42 & 38 & 40 & 28 & 27 \\
\hline commerce and trading & 147 & 129 & 129 & 142 & 110 & 92 & 106 & 63 & 60 \\
\hline banks and financial leasing & 134 & 103 & 65 & 59 & 47 & 49 & 44 & 46 & 29 \\
\hline securities & 26 & 26 & 27 & 23 & 17 & 20 & 20 & 25 & 15 \\
\hline insurance & 14 & 14 & 14 & 14 & 14 & 14 & 14 & 14 & 14 \\
\hline real estate & 17 & 26 & 13 & 12 & 12 & 9 & 11 & 12 & 2 \\
\hline transportation and communication & 83 & 56 & 46 & 32 & 26 & 19 & 22 & 39 & 8 \\
\hline television station & 4 & 4 & 4 & 3 & 4 & 4 & 4 & 3 & 2 \\
\hline electric power companies and gas companies & 15 & 2 & 3 & 2 & 1 & 2 & 2 & 2 & 1 \\
\hline service & 49 & 45 & 45 & 39 & 27 & 25 & 31 & 17 & 8 \\
\hline total & 1,515 & 1,377 & 1,348 & 1,182 & 1,035 & 967 & 961 & 657 & 551 \\
\hline
\end{tabular}

\begin{tabular}{|c|c|c|c|c|c|c|c|c|c|}
\hline Type of industry & $\begin{array}{l}0 \\
0 \\
0 \\
1\end{array}$ & 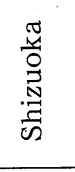 & $\begin{array}{l}\mathbb{J} \\
\mathbb{J} \\
\mathbb{N} \\
\mathbb{J} \\
\mathbb{N}\end{array}$ & $\begin{array}{l}\underset{\pi}{\pi} \\
: 0 \\
\vdots \\
Z\end{array}$ & $\frac{\pi}{3}$ & 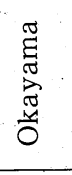 & \begin{tabular}{l}
0 \\
0 \\
0 \\
\multirow{2}{*}{}
\end{tabular} & $\stackrel{\varpi}{\stackrel{\Xi}{\Xi}}$ & 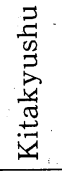 \\
\hline agriculture, fisheries and forestry & & 4 & 4 & 4 & 3 & 5 & 1 & 4 & 3 \\
\hline mining & & & & & & 1 & & & 1 \\
\hline construction & 96 & 75 & 71 & 90 & 106 & 68 & 76 & 56 & 70 \\
\hline food & 33 & 35 & 31 & 29 & 27 & 37 & 32 & 27 & 15 \\
\hline textiles & 5 & 7 & 7 & 9 & 4 & 3 & 7 & 4 & \\
\hline paper and allied products & 1 & 4 & 3 & 4 & 3 & 3 & 1 & 1 & 5 \\
\hline chemicals & 38 & 56 & 52 & 55 & 46 & 42 & 50 & 39 & 29 \\
\hline rubber goods and ceramics & 13 & 13 & 8 & 11 & 13 & 12 & 5 & 9 & 20 \\
\hline iron, steel and machinery & 96 & 142 & 147 & 134 & 107 & 128 & 101 & 109 & 99 \\
\hline other manufactures & 20 & 26 & 26 & 20 & 21 & 24 & 21 & 20 & 10 \\
\hline commerce and trading & 53 & 51 & 52 & 46 & 53 & 47 & 46 & 41 & 41 \\
\hline banks and financial leasing & 52 & 29 & 25 & 26 & 28 & 34 & 48 & 42 & 37 \\
\hline securities & 20 & 15 & 14 & 15 & 15 & 19 & 23 & 13 & 12 \\
\hline insurance & 14 & 14 & 14 & 14 & 14 & 14 & 13 & 12 & 9 \\
\hline real estate & 9 & 2 & 4 & 3 & 5 & 2 & 5 & 4 & 1 \\
\hline transportation and communication & 37 & 7 & 14 & 11 & 16 & 12 & 12 & 7 & 17 \\
\hline television station & 3 & 3 & 3 & 2 & 2 & 2 & 3 & 2 & 1 \\
\hline electric power companies and gas companies & 2 & 1 & 1 & 2 & 2 & 1 & 2 & 1 & 2 \\
\hline service & 14 & 10 & 9 & 6 & 16 & 12 & 12 & 11 & 5 \\
\hline total & 506 & 494 & 485 & 481 & 481 & 466 & 458 & 402 & 377 \\
\hline
\end{tabular}

Source: See Table 2. 
the highest number of branch offices responsible for the whole Shikoku region are concentrated (Figure 1).

Finally, let us make some observations about the construction, transportation and communication sectors. In the construction sector, the cities of Omiya, Kawasaki and Kitakyushu have fewer branch offices, the reason for this being that these three cities are not prefectural capitals. Most construction company branch offices are located in prefectural capitals, because this greatly increases their chances of winning public works contracts in those prefectures.

As for the transportation and communication sector, it is natural that firms in this sector should establish a large number of branch offices in Tokyo, Osaka, and Nagoya, given that each of these cities has a large population, intense economic activity and port facilities. Similarly, firms in the transportation sector have quite a large number of branch offices in Yokohama and Kobe, two cities which have traditionally been outports of Tokyo and Osaka, respectively.

\section{City territories as branch office activity zones}

In this section, we shall focus on the territory of cities, defined from the point of view of areas of activities covered by the branch offices of private firms. Two principal roles are reserved for the branch offices of private firms: the sale of products and information collection. Each branch office is responsible for an area determined according to the marketing strategy developed by a firm's management. Taking Japan as a whole as market, each branch office is responsible for a specific part of the market corresponding to a geographic area, defined in terms of optimum efficiency by the management strategy. It is the area of activity of a branch office that determines the city's territory.

No data being available on the area of activity of branch offices, questionnaires were sent to firms in 19902, the findings from which are shown in Table 7. The results of the 1990 survey are used in this study. This table shows, for example, that of the 80 branch offices located in Sendai, 76, or $95.0 \%$, are also responsi- ble for the prefecture of Aomori. Similarly, of 95 branch offices located in Tokyo, 16, or $16.8 \%$, are responsible for the prefecture of Aomori.

Thus, it is somewhat difficult to define the areas of activity of branch offices by city, because these activities often cross prefectural borders.

All branch offices located in Sapporo cover Hokkaido. In contrast, the proportion of branch offices located in Tokyo responsible for the prefectures of Ibaraki and Tochigi is $82.1 \%$ and $71.6 \%$ respectively: quite low figures. The reason for this is that branch offices in Mito and Utsunomiya are responsible for the prefectures of Ibaraki and Tochigi, with the result that these two prefectures are excluded from the area of activity of branch offices in Tokyo. Of course, the branch offices in Mito and Utsunomiya remain under the control of those in Tokyo.

This point is particularly important where the relationship between branch offices in $\mathrm{Na}$ goya and those in the Hokuriku region is concerned. Whereas the proportion of branch offices located in Nagoya responsible for the prefectures of Toyama, Ishikawa and Fukui are $29.0 \%, 30.0 \%$ and $30.5 \%$ respectively, more than $80 \%$ of the branch offices in Kanazawa and Toyama are responsible for the Hokuriku region. Although the influence of the branch offices in Nagoya on the Hokuriku area appears weak, in reality this is inaccurate, because branch offices in Nagoya enjoy a superior hierarchical status to branch offices in Kanazawa and Toyama (Table 5 and Figure 3).

The criterion which ties a territory to a given city must now be specified and the following criterion appears reasonable: in a given city, if the proportion of branch offices which cover the entire prefecture is greater than $50 \%$, that prefecture will belong to the territory of that city. According to this criterion, the territories of major cities are thus: Sapporo-okkaido; Sendai-he six prefectures in the Tohoku region; Tokyo-he six prefectures in the Kanto region and the prefectures of Yamanashi, Niigata and Nagano; Nagoya-he prefectures of Aichi, Gifu, Mie and Shizuoka; Kanazawa-he prefectures of Toyama, Ishikawa and Fukui; Toyama-he pre- 
Table 7. Percentage of coverage by branch office

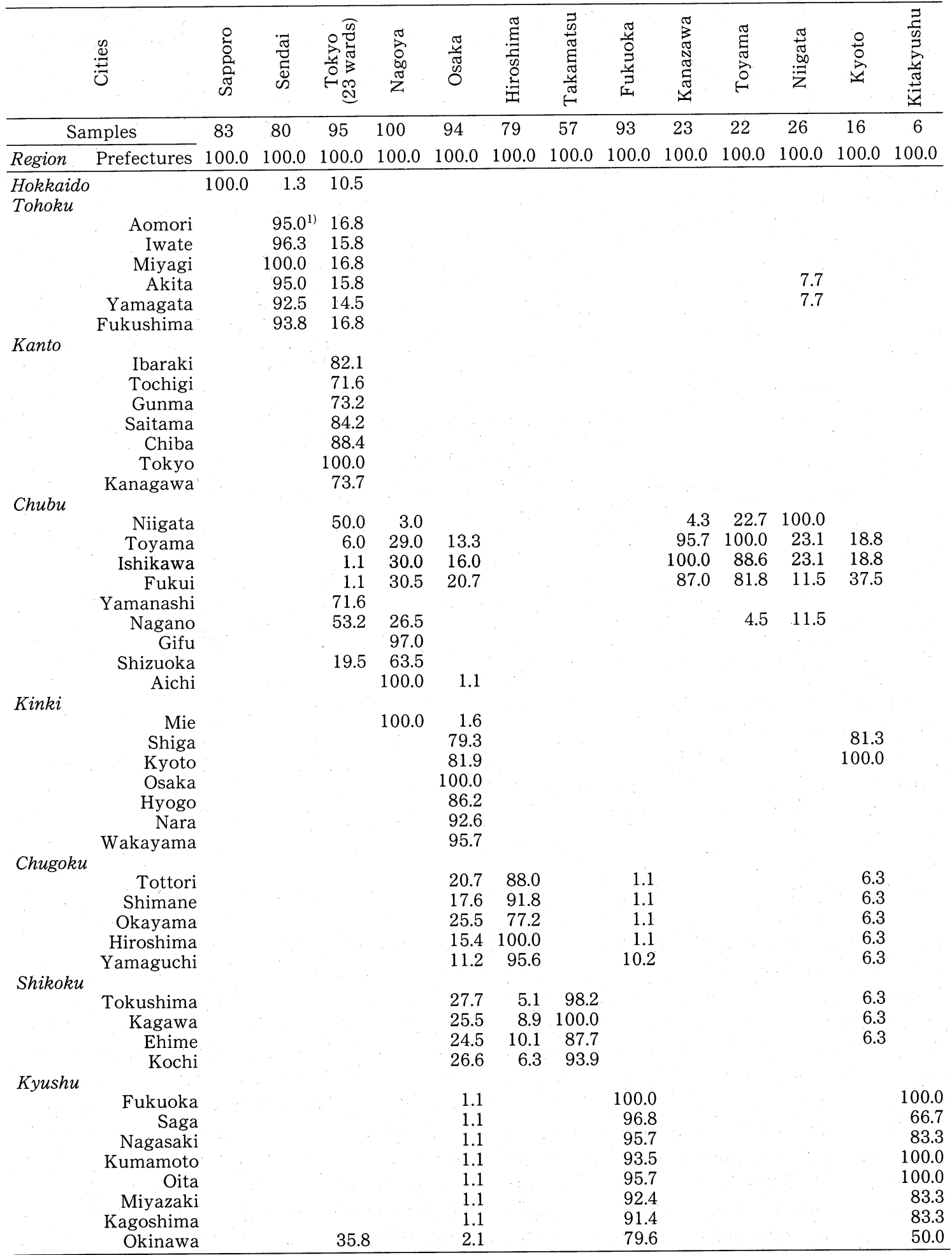

1) $95.0 \%$ of the 80 branch offices (76) located in Sendai are responsible for Aomori Prefecture.

Source: Survey carried out by the author. 


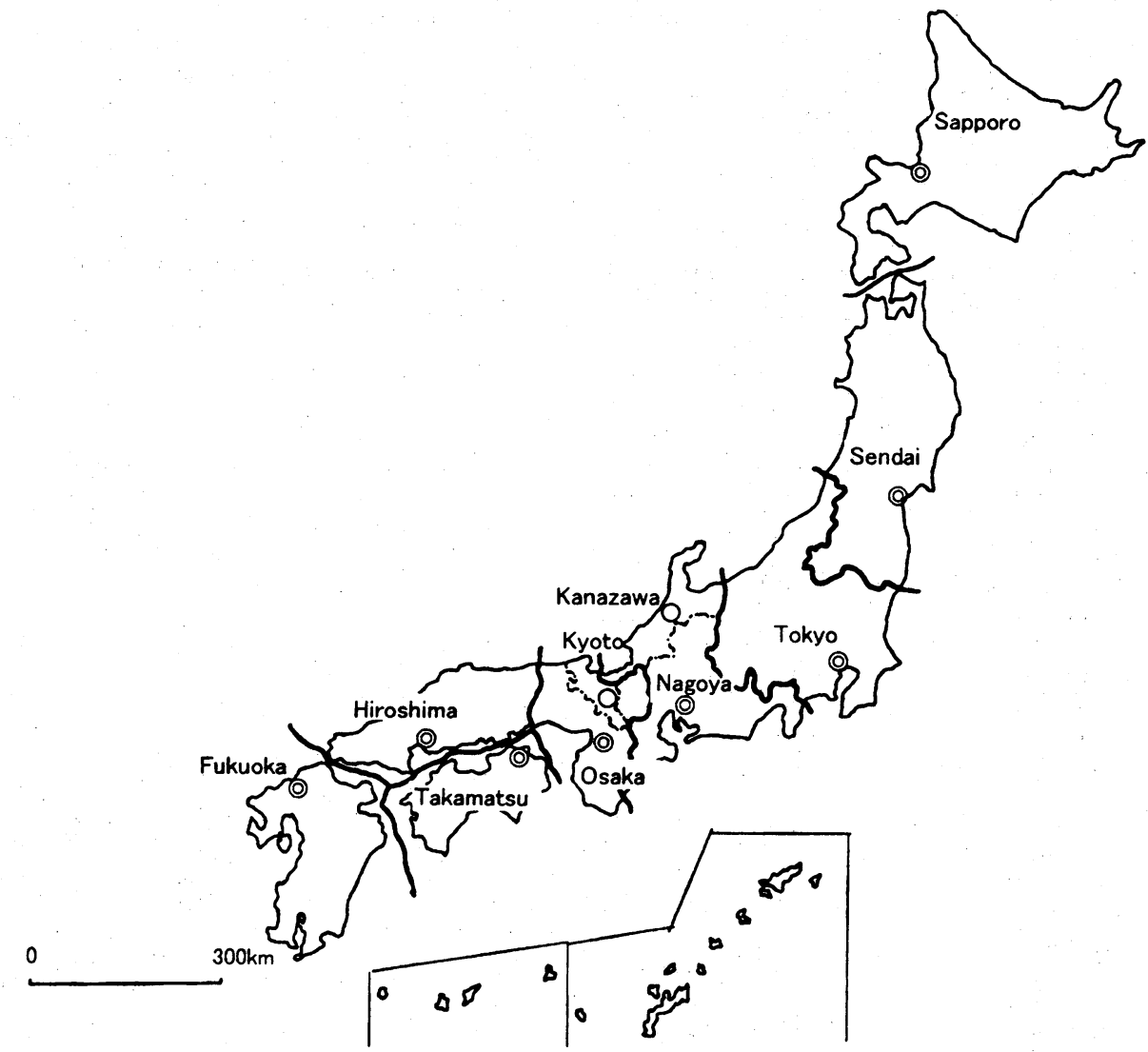

Figure 4. Major cities and their territories served by branch offices. Notes:

(0) First rank city.

- More than $50 \%$ of branch offices in first rank cities cover this area.

--- More than $50 \%$ of branch offices in the cities $(\bigcirc)$ cover this area.

Most branch offices of these cities $(O)$ are under the direction of branch offices located in first rank cities.

Okinawa is included in the territory of Fukuoka.

Small Japanese islands are not shown on this map.

fectures of Toyama, Ishikawa and Fukui; Kyoto -he prefectures of Kyoto and Shiga; Osaka-he prefectures of Osaka, Kyoto, Shiga, Hyogo, Nara and Wakayama; Takamatsu-he four prefectures on the island of Shikoku; Hiroshima-he five prefectures in the Chugoku region; Fukuoka-he seven prefectures on the island of Kyushu and Okinawa prefecture; and Kitakyushu-he seven prefectures on the island of Kyushu and Okinawa prefecture.

Regarding Kitakyushu, the sample size does not make it possible to assert conclusively that the branch offices of this city cover the seven prefectures on the island of Kyushu and Oki- nawa prefecture. As stated earlier, more branch offices located in Kitakyusyu, Kanazawa, Toyama, and Kyoto come under the control of branch offices in Fukuoka, Nagoya and Osaka, than enjoy an equal and independent status. According to the above criterion on territorial possession, Tokyo, Osaka, Nagoya, Sapporo, Sendai, Hiroshima, Takamatsu and Fukuoka have first rank status (Figure 4).

The cities of Kanazawa and Toyama have a territorial coverage of more than $50 \%$ (indeed more than $80 \%$, if we look at the figures in Table 7) of their respective prefectures. Kyoto also covers the prefectures of Kyoto and Shiga, 
yet in fact numerous branch offices located in Kyoto actually come under the control of Osaka. Moreover, while Kanazawa has a high territorial coverage in the prefectures of Toyama, Ishikawa and Fukui, the level of independence of its branch offices is somewhat low because most of them come under the direction of branch offices in Nagoya. It is for this reason that Kanazawa and Kyoto are not included in the list of first rank cities. In addition, Toyama can not be ranked at the same level as Kanazawa, as fewer branch offices are located there (Table 2). Consequently, only Kyoto and Kanazawa have second rank status. Figure 4 shows first and second rank cities and their territories.

We shall now analyze the factors that have influenced the process of city territory formation. Three factors can be indicated. The first is natural geographic setting. Hokkaido, Shikoku and Kyushu, for example, form separate regional territories because Japan comprises 4 main islands (Figure 1). The second factor is historical; that is, certain historical traditions exist, which were taken into consideration by firms, along with the geographical factor, when they defined their areas of activity in the six prefectures comprising the Tohoku region and the five prefectures comprising the Chugoku region. However, it is not easy to divide this part of Honshu, extending from Kanto to Kinki. There is simply no consensus about this. For example, although the Chubu region (Figure 1) comprises the prefectures of Niigata, Nagano, and Yamanashi in the north (Figure 1), these prefectures are actually strongly linked to Tokyo, in what is called the outer Kanto region. Similarly, although the prefecture of Mie is part of the Kinki region (Figure 1), it is actually linked to Nagoya.

The prefectures of Toyama, Ishikawa and $\mathrm{Fu}$ kui in the Hokuriku region show characteristics which indicate a measure of independence, while at the same time being exposed to rival influences from Osaka and Nagoya, and in fact the region is actually linked to Osaka and $\mathrm{Na}$ goya.

The third factor is of an administrative nature: the influence of the central administrative offices. Administrations exercise considerable influence on economic activities because of their license system, and although the influence of administrations is not in itself the object of the present study, it can be noted that private firms choose to carry out their activities in the corresponding administrative areas as much as possible.

Table 8 and Figure 5 show the territorial division of Japan into spheres of influence by thirty national government authorities. It is noteworthy that these spheres of influence are almost identical to private firm areas of activity.

The demarcation of Japan by national government authority is also, without doubt, the result of historically based concepts of territory, and connected with the physical geography of Japan. In the Hokuriku region, there is, however, a difference between the territorial demarcation of the activity areas of the branch offices of private firms and the demarcation by national government authority. Our criterion allocates a sphere of influence to a city if more than fifteen representative agencies of national government authority cover it (that is, more than 50\%). Nagoya easily covers more than $50 \%$ the prefectures of Toyama and Ishikawa, but does not reach this level in the case of Fukui prefecture. This exception aside, the areas of activity of the branch offices of private firms and the spheres of influence of the branch offices of central government authorities are fundamentally identical.

\section{Head office and branch office size}

No reference has been made, during the preceding analyses, to the size of head and branch offices. For example, a branch office employing 500 people or one employing only 5 has been counted as one branch office. Obviously, the difference in size of branch offices is important because size corresponds to the level of economic power of a city and of its territory. In the next chapter, this relationship will be illustrated by a model diagram of the Japanese urban system using the 18 major Japanese cities.

The reference materials used are the annual financial statements for 1995 , submitted to the Japanese Ministry of Finance by the firms under study. Although it is impossible to confirm 
Table 8. Percentage of coverage by national administrative office

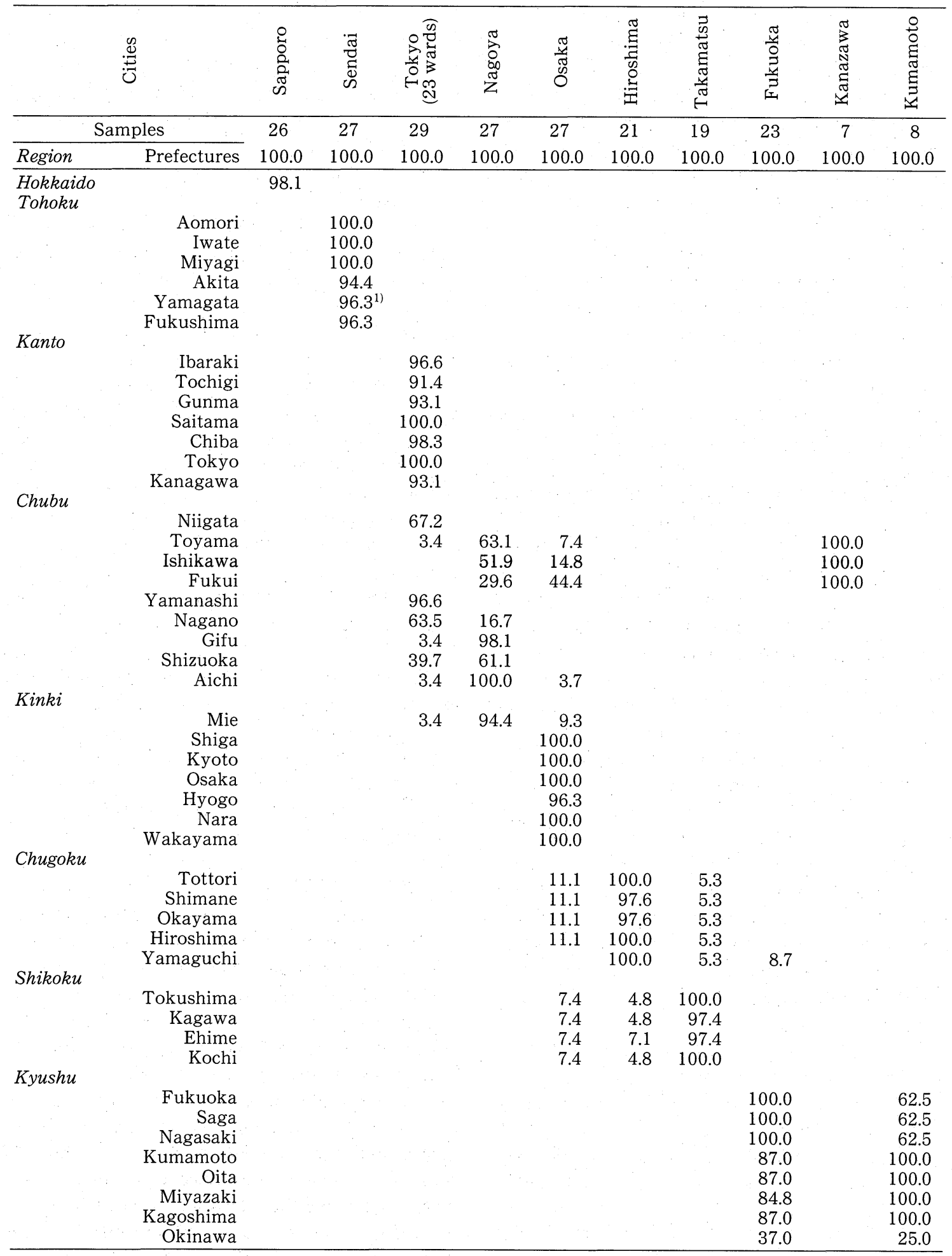

\footnotetext{
1) $96.3 \%$ of the 27 branch offices (26) located in Sendai are responsible for Yamagata Prefecture.
} Source: Survey carried out by the auther. 


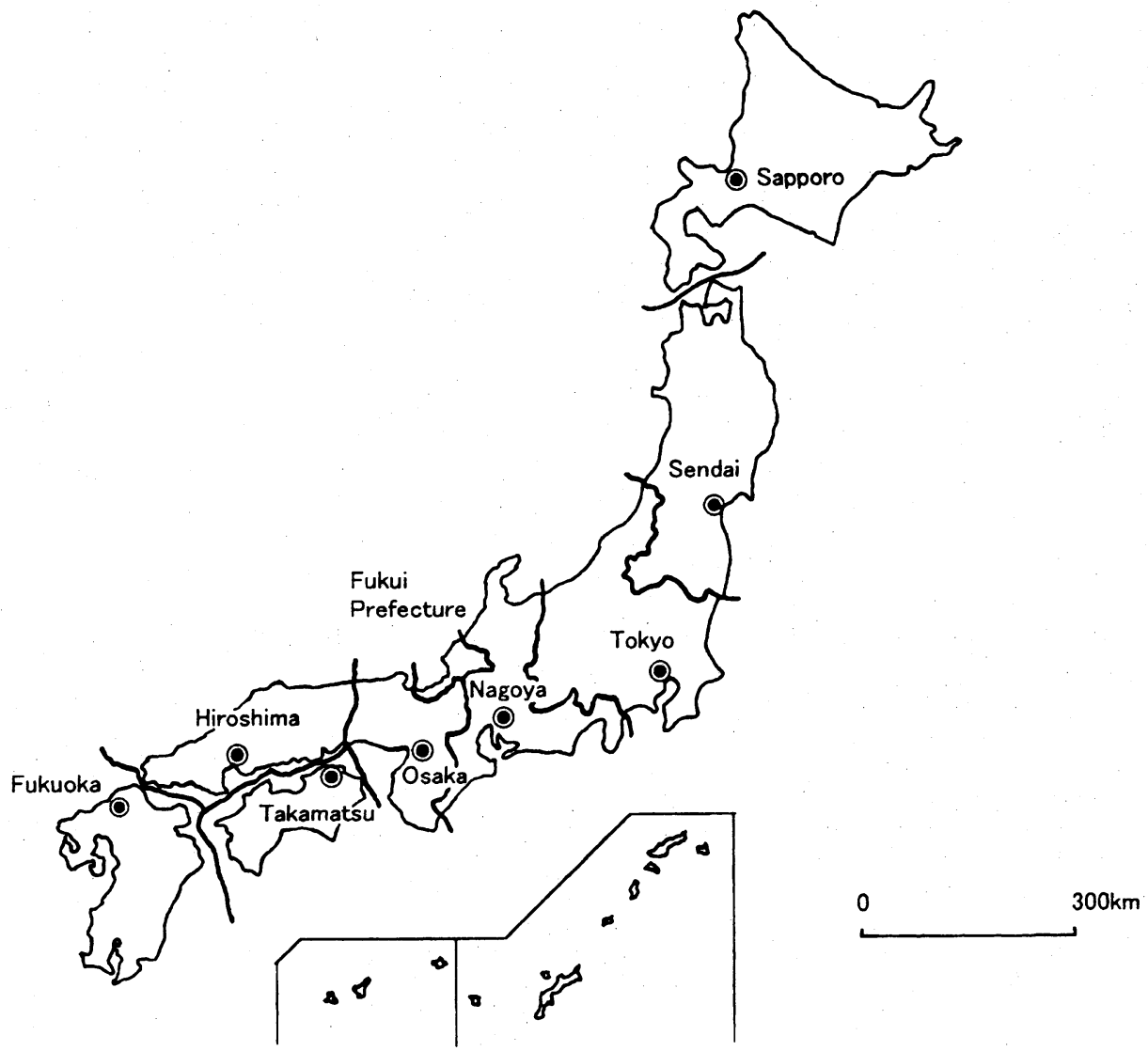

Figure 5. Major cities and their territories served by administrative responsibility of national government offices in major cities.

Notes:

- First rank city

- More than $50 \%$ of repesentatives of national government in cities marked $\bigcirc$ cover this area.

No city has more than 15 (ie., more than $50 \%$ ) representatives of national government covering the prefecture of Fukui.

the number of employees in the head and branch offices of all private firms, it can be said that these reports provide the best information for a detailed study and are in fact the most reliable sources of information regarding the number of employees of private firms.

Table 9 shows the average number of employees in the head and branch offices of firms in the 18 major Japanese cities. The average number of employees in head offices is highest in Tokyo, where it is 653.9 people. Tokyo, therefore, ranks first, both in terms of number of head offices and in terms of their size. The head offices located in Sapporo, Sendai, Hiroshima and Fukuoka are also large, because large local companies, such as electricity, gas companies and banks have head offices in these cities, with clearly marked areas of activity. The same phenomenon can be observed in $\mathrm{Na}$ goya, despite the fact that the number of head offices is much lower than the number in Tokyo and Osaka.

In Kobe and Kyoto, the average number of employees in the head offices of large firms is rather small, the reason being that few large firms have head offices there, most head offices employing less than 250 employees. Though there are firms in these two cities that have been established there for many years, there are no electricity or large gas company head offices likely to raise the average number of employees per head office. 
Table 9. Number of employees in head offices and branch offices in 18 cities

\begin{tabular}{|c|c|c|c|c|c|c|}
\hline & A & B & $\mathrm{C}$ & D & $\mathrm{E}$ & $\mathrm{F}$ \\
\hline Tokyo (23wards) & 919 & 653.9 & 1,515 & 225.7 & 942,870 & 100.0 \\
\hline Osaka & 314 & 502.2 & 1,377 & 142.7 & 354,189 & 37.3 \\
\hline Nagoya & 88 & 539.1 & 1,348 & 82.8 & 159,055 & 16.9 \\
\hline Fukuoka & 33 & 527.2 & 1,182 & 75.0 & 106,048 & 11.2 \\
\hline Yokohama & 50 & 523.3 & 657 & 100.2 & 91,996 & 9.8 \\
\hline Sendai & 9 & 532.8 & 1,035 & 69.0 & 76,210 & 8.1 \\
\hline Hiroshima & 21 & 414.2 & 967 & 57.0 & 63,817 & 6.8 \\
\hline Sapporo & 24 & 502.3 & 961 & 52.1 & 62,123 & 6.6 \\
\hline Kobe & 57 & 389.1 & 506 & 70.6 & 57,903 & 6.1 \\
\hline Kyoto & 48 & 278.4 & 458 & 76.4 & 48,354 & 5.1 \\
\hline Chiba & 9 & 5.12 .4 & 481 & 80.3 & 43,236 & 4.6 \\
\hline Kitakyushu & 16 & 445.7 & 377 & 67.3 & 32,503 & 3.4 \\
\hline Niigata & 9 & 599.1 & 481 & 56.1 & 32,376 & 3.4 \\
\hline Takamatsu & 10 & 320.7 & 551 & 48.6 & 29,986 & 3.2 \\
\hline Omiya & 5 & 257.7 & 402 & 61.1 & 25,851 & 2.8 \\
\hline Shizuoka & 4 & 375.8 & 494 & 49.8 & 26,104 & 2.7 \\
\hline Kanazawa & 11 & 217.6 & 485 & 43.2 & 23,346 & 2.5 \\
\hline Okayama & 7 & 368.5 & 466 & 34.3 & 18,564 & 2.0 \\
\hline
\end{tabular}

Cities are ranked by the value of $\mathrm{F}$.

A. Number of head offices

B. Average number of employees in head offices

C. Number of branch offices

D. Average number of employees in branch offices

E. $\mathrm{A} \times \mathrm{B}+\mathrm{C} \times \mathrm{D}$

F. In column $\mathrm{E}$, Tokyo is given the base value of 100.0 .

Sources: i) The number of employees in head offices is the number indicated in annual company reports. ii) The number of employees in branch offices is the number indicated in annual company reports.

Concerning the size of branch offices, Tokyo has the highest average number of employees per branch office, just as it does for head offices. Osaka has the second highest, followed by Yokohama, Nagoya, Chiba, Kyoto, Fukuoka and Kobe. Each of these cities except Chiba has more than one million inhabitants (Table 2). The territories of the branch offices located in Yokohama, Kyoto and Kobe are limited. However, the size of these branch offices is in proportion with the size of the population of these cities and their activity, which indicates that many firms operate on a large scale there.

\section{The Japanese Urban System}

Inter-urban connectivity analyzed from the point of view of the location of private firm branch offices

The 18 major Japanese cities mentioned earlier form the basis for the present study. Analy- sis is based on an overall view of the location of branch offices, deliberately ignoring the different patterns of location, even though these vary depending on type of industry of given firms. The branch offices of the firms that have head offices in Tokyo, Osaka and Nagoya are analyzed in the study (Table 10).

The highest number of branch offices dependent on head offices based in Tokyo are located in Osaka, with 681 (74.1\% of the total number of firms having head offices in Tokyo). The number of branch offices in Tokyo dependent on head offices based in Osaka is 269 (85.7\% of the total number of firms having head offices in Osaka). Head offices in Nagoya have 62 branch offices in Tokyo $(70.5 \%$ of the total number of firms having head offices in Nagoya). Of the total number of firms having head offices in Tokyo, $70.1 \%$ have branch offices in Nagoya, as do $69.4 \%$ of the total number of firms having head offices in Osaka. The percentage of inter- 
The Japanese Urban System

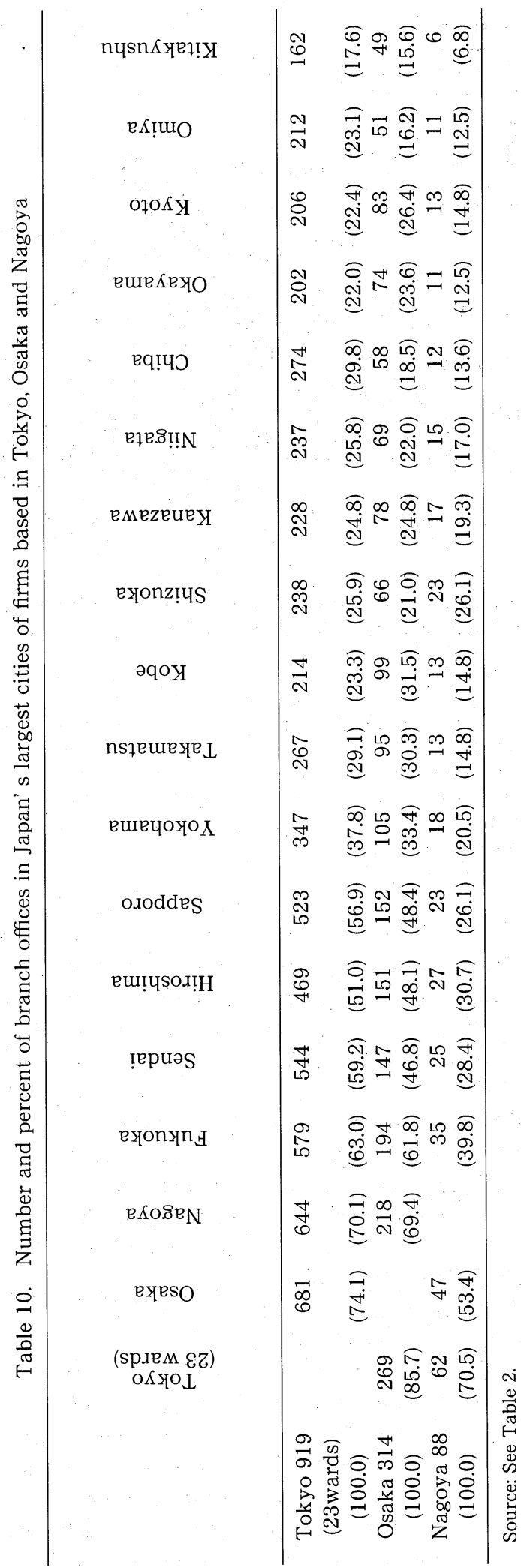




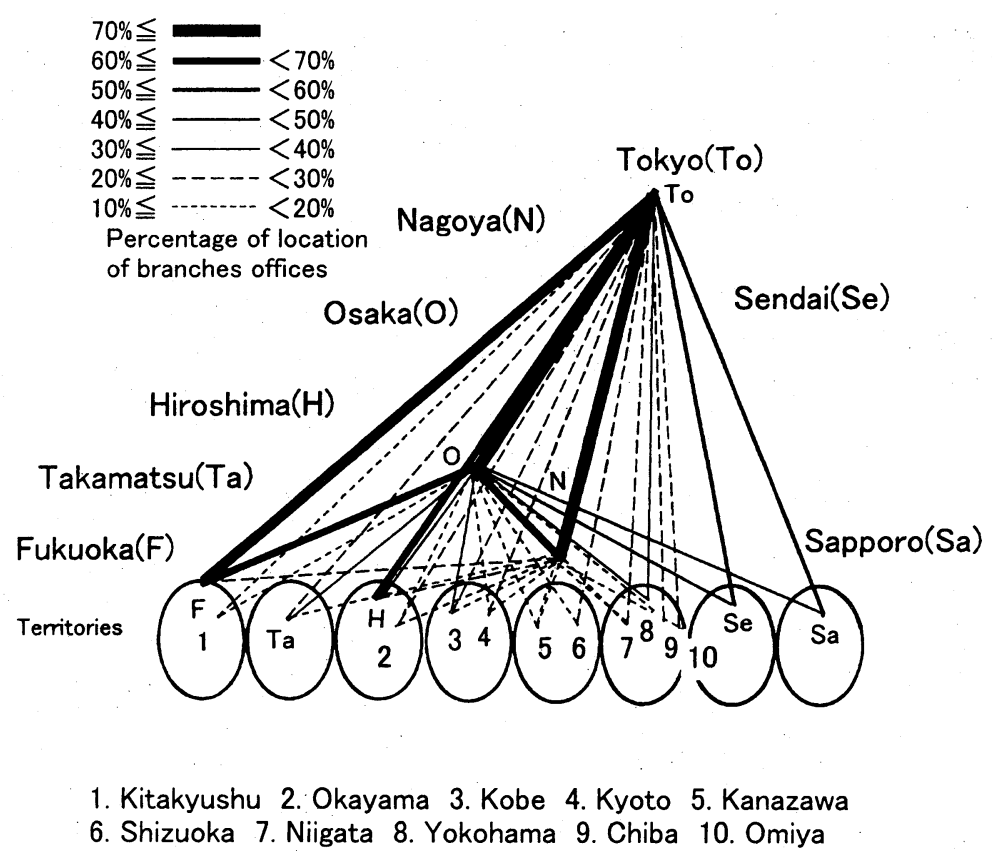

Figure 6. The Japanese urban system.

Notes:

1) Ellipses indicate the territories of Fukuoka, Takamatsu, Hiroshima, Osaka, Nagoya, Tokyo, Sendai and Sapporo (Figure 4).

2) The vertical position of each city is determined on the basis of the number of employees in head offices and branch offices located in Tokyo (Column $\mathrm{F}$ in Table 9).

3) Lines indicate the percentage of branch offices of firms based in Tokyo, Osaka and Nagoya in major Japanese cities.

connectivity of branch offices by firms having their head offices in these three cities is particularly high, with the exception of the percentage of connectivity of branch offices in Osaka by firms having their head offices in Nagoya, which is only $53.4 \%$. Considering that the percentage of connectivity of branch offices in Tokyo by firms having their head offices in Nagoya is $70.5 \%$, it can be deduced that firms in Nagoya noticeably treat Osaka less seriously than they do Tokyo.

Between $51.0 \%$ and $63.0 \%$ of the firms based in Tokyo have branch offices in Sapporo, Sendai, Hiroshima and Fukuoka. However, only between $46.8 \%$ and $48.4 \%$ of the firms based in Osaka have branch offices in Sapporo, Sendai and Hiroshima. Of the firms based in Tokyo, $63.0 \%$ and $51.0 \%$ have branch offices in $\mathrm{Fu}$ kuoka and Hiroshima, whereas $61.8 \%$ and $48.1 \%$ of the firms based in Osaka have branch offices there. This is 8.5-12.4 points more than in the case of Sapporo and Sendai. The influence of Osaka is weak in the north part of Japan. Firms in Nagoya also have a relatively small number of branch offices in Sapporo. The influence of Nagoya is weak except in Tokyo and Fukuoka.

To conclude, Tokyo, Osaka, Nagoya, Sapporo, Sendai, Hiroshima and Fukuoka are the cities where the largest number of firms based in Tokyo, Osaka and Nagoya have established branch offices.

\section{A tentative model for the Japanese urban sys- tem}

We shall now try to compose a model for the urban system using these 18 cities, based on the findings in the preceding analyses. Figure 6 takes as variables the number of head offices based in Tokyo, Osaka and Nagoya, and branch offices in each city, their territories, and the percentage of location of branch offices in re- 
spect to firms with head offices in Tokyo, Osaka and Nagoya.

The percentage of inter-connectivity of branches between Tokyo, Osaka and Nagoya is the average value of the inter- connectivity of branch offices of each pair of cities. The vertical position of each city is determined by taking as indicator the number of employees in head offices and branches located in Tokyo (Column $\mathrm{F}$ in Table 9).

\section{Conclusion}

In this paper we set out to analyze the situation of the head offices and branch offices of private firms in major Japanese cities. The study covered 2,241 large Japanese firms. The number of head offices is considerably higher in Tokyo than in the other cities $(919$, or $41.0 \%$ of the total number of head offices). Osaka, in second place, has 314 head offices (14.0\%), followed by Nagoya with 88 (3.9\%). These three cities alone account for $58.9 \%$ of all head offices. The heavy concentration of head offices in Tokyo can be explained by its many advantages, which also explain why it is very common for firms to establish their second head offices in Tokyo.

Tokyo also houses the largest number of branch offices, followed by Osaka then Nagoya. Fukuoka, Sendai, Hiroshima, Sapporo, and to a lesser extent Takamatsu, also have a large number of branch offices. These cities are located in suitable positions for a rational distribution of company activities at the regional level to apply. The concentration of functions in these 5 regional capitals and in Tokyo, Osaka and $\mathrm{Na}-$ goya is strongly linked to their territories.

Yokohama, Kyoto and Kobe, despite having large populations, have relatively few branch offices because of their limited areas of activity. For this reason, they are integrated into the agglomerations of Tokyo and Osaka. Most of the firms with branches in these three cities operate in the banks and financial leasing, insurance and construction fields, where relations with citizens and prefectural administrations are privileged. Nevertheless, the main characteristics of the eight cities above is that they house a large number of branches in the field of manufacturing, as well as in the fields of banks and financial leasing, insurance and construction.

On the organization chart of a company, the head office dominates, controlling all others. However, hierarchical relationships also exist between branch offices, depending on the importance of the cities and their territories.

We have proposed a model for the urban system, based on variables gathered from the several analyses carried out, which showed the sites of branch offices with head offices in Tokyo, Osaka and Nagoya. The results of these analyses are shown in Figure 6. This figure clearly shows the complex networks of interconnectivity established between major Japanese cities by large firms based in Tokyo, Osaka and Nagoya, as well as the level of importance of Japanese cities in this respect, with the undisputed dominance of Tokyo.

\section{Acknowledgement}

Thanks are due to Prof. Risto Laulajainen for his beneficial suggestions and comments.

(Received July 19, 1999)

(Accepted April 26, 2000)

\section{Notes}

1. Interviews and questionnaires were conducted at firms other than banks, financial leasing, securities, and insurance companies, television stations and electric power and gas companies. Valid responses were obtained from $100 \mathrm{com}$ panies.

2. Interviews and questionnaires were conducted at firms other than banks, financial leasing, securities and insurance companies, television stations and electric power and gas companies. The number of valid responses is listed under each city in Table 7.

\section{References}

Abe, K. 1977. L'accumulation des fonctions de gestion des affaires economiques vue des maisons-méres et filiales des grandes entreprises. Geographical Review of Japan 50A: 362-369. (JF)

Abe, K. 1979. Economic management function. In Ryutsu jyoho no chiikikozo (Regional structure of circulation and information), ed. Y. Kitamura and A. Terasaka, 241-250. Tokyo: Taimeido. (J)

Abe, K. 1984. Head and branch offices of big private 
enterprises in major cities of Japan. Geographical Review of Japan 57B: 43-67. (EJ)

Abe, K. 1990. The status of Tokyo in Japan from the standpoint of high-order urban function. Geographical Review of Japan 63B: 17-24. (EJ)

Abe, K. 1991. Nihon no toshi taikei kenkyu (A study on the urban systems in Japan). Kyoto: Chijin Shobo. (J)

Abe, K. 1996. Senshinkoku no toshi taikei kenkyu ( $A$ study on the urban systems in the advanced countries). Kyoto: Chijin Shobo. (J)

Economic Planning Agency 1964. Chusu-kanrikino ni kansuru chosa (A study on the economic management function). Tokyo: (J)

Komori, T. 1965. Kigyo honsha no Tokyo shuchu (Concentration of head offices in Tokyo). In To- shimondai koza 1 (Urban Problems Seminar 1). ed, H. Iwai, I. Kato, T. Shibata, and Y. Yasoshima, 193-206. Tokyo: Yuhikaku. (J)

Nagai, S. 1967. Chiiki betsu keizai hatten no doko (Trends of economic growth by region). In Toshi kaihatsu koza I (Urban Development Seminar I), ed. S. Okita, 9-55. Tokyo: Kashima-shuppan-kai. (J) Nagai, S. and Miyaji, O. 1967. Chusu kanri kino to toshi no saihensei (Central management function and urban restructuring). In Chiiki kaihatsu no keizai (Economics of regional development), ed. S. Okita, 91-126. Tokyo: Chikuma Shobo. (J)

Takahashi, N. 1983. Kinyu no chiki kozo (The Regional Structure of Financial Activities). Tokyo: Taimeido. (J) 